OPEN ACCESS

Edited by: Kohei Hasegawa,

Massachusetts General Hospital and

Harvard Medical School,

United States

Reviewed by:

Michael Adam O'Reilly,

University of Rochester, United States

Ravi Misra,

University of Rochester, United States

*Correspondence:

Yujia Wang

15881424997@163.com

Specialty section

This article was submitted to

Pulmonary Medicine

a section of the journal

Frontiers in Medicine

Received: 20 August 2021

Accepted: 13 October 2021

Published: 05 November 2021

Citation:

$X i Y$ and Wang $Y(2021)$ Insight Into the Roles of Non-coding RNA in Bronchopulmonary Dysplasia.

Front. Med. 8:761724.

doi: $10.3389 /$ fmed.2021.761724

\section{Insight Into the Roles of Non-coding RNA in Bronchopulmonary Dysplasia}

\author{
Yufeng $\mathrm{Xi}^{1}$ and Yujia Wang ${ }^{1,2 *}$ \\ ${ }^{1}$ Department of Neonatology, Chengdu Women's and Children's Central Hospital, School of Medicine, University of \\ Electronic Science and Technology of China, Chengdu, China, ${ }^{2}$ Department of Dermatology, State Key Laboratory of \\ Biotherapy, West China Hospital, Sichuan University, Chengdu, China
}

Bronchopulmonary dysplasia (BPD) is a chronic lung disease most commonly occurring in premature infants, and its pathological manifestations are alveolar hypoplasia and dysregulation of pulmonary vasculature development. The effective treatment for BPD has not yet been established. Non-coding RNAs, including microRNAs and long non-coding RNAs do not encode proteins, but can perform its biological functions at the RNA level. Non-coding RNAs play an important role in the incidence and development of BPD by regulating the expression of genes related to proliferation, apoptosis, angiogenesis, inflammation and other cell activities of alveolar epithelial cells and vascular endothelial cells. Here we summarize the role of non-coding RNAs in BPD, which provides possible molecular marker and therapeutic target for the diagnosis and treatment of BPD.

Keywords: bronchopulmonary dysplasia, premature infants, noncoding RNA, microRNA, long non-coding RNA

\section{INTRODUCTION}

Bronchopulmonary dysplasia (BPD) (1-4) is an important cause of respiratory illness in preterm newborns that results in significant morbidity and mortality. BPD was first discribed by Northway in 1967, which was caused by oxygen supply and mechanical ventilation in premature infants with severe respiratory distress syndrome (5). The "new" BPD pathology is characterized by arrested alveolar-capillary development with larger, simplified alveoli, increased interstitial fibrosis, and abnormal pulmonary vasculature with decreased branching (1, 6-8). Clinical epidemiological studies (9) show that BPD occurs mostly in premature infants, and the younger the gestational age and the lower the birth weight, the higher the incidence and severity of BPD. Infants with BW $<1,250$ g accounted for $97 \%$ of BPD cases. BPD has an important impact on the respiratory and nervous system, which seriously affects the quality of life of children, and at the same time, it will cause heavy economic burden on the family and society (10). Despite prenatal usage of glucocorticoid (11), pulmonary surfactant (12), moderate ventilation strategy (13) and other methods improve the survival rate and decrease the incidence rate of BPD in premature infants, but BPD remains an important cause of death for very low birth weight infants. Current studies suggest that BPD may be caused by a combination of multiple factors including premature birth $(14,15)$, fetal growth restriction (16), mechanical ventilation (17), oxygen toxicity (18), infection (19), inflammation (20), patent ductus arteriosus (PDA) (21), genes and genetic susceptibility (22) and so on. So far, the etiology and pathogenesis of BPD are not yet clear, thus there is no specific treatment (23). 
Non-coding ribonucleic acid (RNA) refers to RNA that does not encode proteins (24). Non-coding RNA include ribosomal RNA (rRNA) (25), transfer RNA (tRNA) (26), small nuclear RNA (snRNA) (27), small nucleolar RNA (snoRNA) (28), small interfering RNA (siRNA) (29), circular RNA (circRNA) (30), microRNA(miRNA) (31), and long non-coding RNA(LncRNA) (32) with known functions, as well as RNA with unknown functions. The common feature of these RNAs is that they can be transcribed from the genome, but not translated into proteins. However, these non-coding RNAs play an important role in gene expression and disease progression, and they can regulate gene expression at transcriptional or post transcriptional levels. In recent years, molecular biology research has found that non-coding RNAs play an important role in the incidence and development of lung diseases (33), such as lung cancer (34), chronic obstructive pulmonary disease (COPD) (35), asthma (36), respiratory distress syndrome (RDS) (37) and BPD, which provides a new idea for the treatment of diseases (38).

In this review, we summarize the role of non-coding RNAs in $\mathrm{BPD}$, in order to provide possible molecular marker and therapeutic target for the diagnosis and treatment of BPD.

\section{THE ROLES OF NON-CODING RNA IN BPD MiRNA}

MicroRNA (miRNA) is a class of endogenous non-coding single stranded RNA with a length of about 20-24 nucleotides (39). It regulates gene expression by inhibiting translation or mediating the degradation of target mRNA at the post transcriptional level (40). Each miRNA can have multiple target genes, and several miRNAs can regulate the same gene at the same time. Studies have shown that miRNAs can regulate $30 \%$ of all genes in the human genome and play an important role in various biological processes, including cell proliferation, differentiation and apoptosis, metabolism, tissue damage and repair, biological development and tumor occurrence and development (41). More and more research suggest miRNA has been involved the incidence and development of BPD, and the summary is as follows.

MiR-17 92 clusters are needed to be appropriately expressed in normal lung growth and development, and changes in miR17 92 clusters have also been reported in other lung diseases (42, 43). Data from severe BPD murine model suggested that the expression of miR-17 92 cluster in lung tissue is downregulated (44), meanwhile, autopsy tissue data suggested that the expression of miR17 92 is lower in BPD lung tissue than that in normal lung tissue, and is inversely correlated with promoter methylation and DNA methyltransferase expression. In addition, miR-17 and miR-19b expression was decreased in plasma sample in infants with BPD (45). MiR-17 92 clusters have been shown to regulate transforming growth factor$\beta$ (TGF- $\beta$ ), matrix metalloproteinases (MMPs), and Collagen III alpha 1 (COL3A1). Alter of matrix composition will decrease alveolarization and pulmonary function as observed in infants with severe BPD and in our murine model.

In the mouse model of BPD, hyperoxia exposure was associated with increased S-nitrosoglutathione (GSNO) catabolism by increasing the expression of GSNOR in the lungs. It is observed that the expression of miR-342-3p is decreased in mice exposed to hyperoxia. One of the mechanisms of upregulation of GSNOR protein expression induced by hyperoxia is via post-transcriptional regulation of miR-342-3p. It has been predicted that this mechanism may be related to other pulmonary toxicities associated with hyperoxia exposure (46).

Previous studies have found that abnormal remodeling of extracellular matrix (ECM) is related to the pathogenesis of BPD (47). Fibronectin 1 (FN1) as a major component of ECM, FN1 also has angiogenesis characteristics and can interact directly and indirectly with other key regulatory factors of ECM, such as TGF- $\beta 1$ and VEGF $(48,49)$. In addition, FN1 is considered to be caused by inflammation $(50,51)$, and many studies have shown that inflammation is associated with an increase in severe $\operatorname{BPD}(52,53)$. The expression of miR-206 in BPD mice tissues and BPD patient tissues is lower than that in normal tissues. Overexpression of miR-206 induced cell apoptosis, reduced cell proliferation, migration and adhesion. And FN1 is the direct target of miR-206. In BPD mice and BPD patients, the expression level of fibronectin 1 is increased. Downregulation of miR-206 increased the expression level of FN1, which played a role in ECM remodeling and contributed to BPD (54).

MiR-29a was significantly increased in the BPD mice lung tissue, and it has been proved direct miR-29a target were further validated using bronchoalveolar stem cells (55).

$\mathrm{Hu}$ Y et al., (56) found that down-regulation of miR-29a can potentially increase GRB2-associated-binding protein 1 (GAB1) expression, reducing cell apoptosis and stimulating proliferation, ultimately retarding the development of BPD in mice. Analysis of plasma in preterm infants with subsequent BPD showed that miR-29b decreased and was negatively correlated with the severity of BPD. The combination therapy of miR-29b with AAV9 as a carrier may hopefully restore normal lung structure in preterm infants with severe BPD (57). Suppression of miR$29 \mathrm{~b}$ expression is related to the increasing of transforming growth factor- $\beta$ (TGF- $\beta$ ), Smad2/3 protein levels, and all of which lead to extracellular matrix (ECM) deposition.

Delta-like 4 (DLL4), a membrane-bound ligand belonging to the Notch signaling family, plays a fundamental role in vascular development and angiogenesis (58). miR-30a regulates endothelial tip cell formation and arteriolar branching by downregulating Dll4 (delta like ligand 4) expression (59). In clinical studies, miR-30a was downregulated in preterm infants with BPD $(60,61)$. These studies indicate that decreased miR-30a expression may be associated with impaired lung development in neonates with BPD. Analysis of the pulmonary transcriptome revealed that miR-30a target angiogenesis-related genes, namely the mechanism is upregulation of miR-30a inhibiting the expression of Dll4 and subsequent downregulation of angiogenesis (61). Another study (62) shows that higher miR30 a expression through hypoxia inducible factor- $1 \alpha$ (HIF-1 $\alpha$ ) decreases Snail expression in females and attenuates injury in the developing lung.

Hyperoxic acute lung injury (HALI) is a key factor in the pathogenesis of BPD. It has been found a significant increase in the level of miR-34a in BPD mice lung tissue. In the model 
of BPD mice, the absence or inhibition of miR-34a improved $\mathrm{BPD}$-related pulmonary hypertension (PAH). Meanwhile, the use of angiopoietin-1 (one of the downstream targets of miR-34a) can improve the pulmonary phenotypes of PAH and BPD. In addition, it has been reported an increase in miR-34a level in type 2 alveolar epithelial cells in neonates with BPD. It suggested that drug-induced miR-34a inhibition may be a therapeutic option for BPD prevention and treatment (63). A study by Ruiz-Camp et al., (64) suggest that miR-34a in platelet-derived growth factor receptor $\alpha$ positive (PDGFR $\alpha+$ ) cells contribute to aberrant lung alveolarization, but global loss of miR-34a partially restores lung alveolarization in experimental BPD.

The expression level of miR-489 in the lung tissue of BPD neonates is lower than that of normal neonates, which is related to increases in its conserved target genes insulin-like growth factor-1 (IGF-1) and tenascin C (Tnc) (65).

Glycoprotein non-metastatic melanoma protein B (GPNMB) is a transmembrane protein, which plays an important role in angiogenesis and tissue repair via inducing autophagy $(66,67)$. And it has been identified as one of the targets of miR-150 (68). The expression of miR-150 decreased in hyperoxia exposure neonatal rat lung tissues. And soluble GPNMB promoted angiogenesis in the hyperoxic neonatal mice lung tissues via miR150 regulation. GPNMB played an important role in angiogenesis during hyperoxia injury and GPNMB therapy can provide a new method to reduce the pathological complications of BPD (69).

Fibroblast growth factor 10 (FGF10) is an important regulator of branching morphogenesis in the early stage of lung development, which is a potential marker for predicting the development of BPD in premature neonates (70, 71). FGF10 has been identified as a target gene for miR-421. The expression of miR-421 was significantly increased in BPD mice lung tissues while the expression of FGF10 is decreased. The upregulation of miR-421 and the silence of FGF10 aggravated the inflammatory response of lung tissue and promoted the apoptosis of Type II alveolar epithelial cell line MLE-12. These changes can be reversed by lowering the expression of miR-421. Inhibiting the expression of miR-421 can be helpful to the development of BPD in mice by upregulating the expression of FGF10. MiR-421 might be possible target for the prevention and treatment of BPD (72).

Adrenomedullin (ADM) (73), an important regulator of oxidative damage, has been reported that it can protect the premature infants with BPD. However, the pathogenesis of $\mathrm{ADM}$ regulating $\mathrm{BPD}$ is not clear. The study (74) finds that the expression of miRNA-574-3p in blood of premature infants with BPD was significantly lower than that of premature infants without BPD. Luciferase reporter gene analysis showed that $\mathrm{ADM}$ is the target gene of miR-574-3p. The increased expression of ADM regulated by miR-574-3p may protect premature infants with BPD and provide new ideas for the prevention and treatment of BPD. However, we need more intervention study to identify the idea.

It has been reported that the expression level of miR-876-3p is lower in BPD mice lung tissues and Human Bronchial Epithelial (NHBE) cells than that in normal tissues and cells. For increased proteobacteria in the airway microbiome is related to BPD, it has been reported a new model combining proteobacterial LPS and hyperoxia exposure. Compared with hyperoxia alone, the add of LPS can significantly reduce the expression of miR-876$3 p$ in NHBE cells, which indicated that the change of microbial community can inhibit the potential mechanism of miR-876$3 \mathrm{p}(75)$.

Let-7, as an important family of Mir family, regulates lung development by regulating cell cycle and cell division related genes. Studies have shown that the decreased expression of Let-7c, a member of the Let-7 family, is closely related to the occurrence of multiple lung diseases (76). Previous studies have shown that lipoxin A4 (LXA4) can inhibit the development of $\mathrm{BPD}$, but the mechanism is not clear. A study by Chen XQ et al., (77), suggested that the LXA4-imparted protective effects on hyperoxia-induced lung injury are mediated by upregulation of Let- $7 c$ and inhibition of transforming growth factor- $\beta 1$ (TGF- $\beta 1$ ) and subsequent downregulation of TGF- $\beta 1$ signaling pathway.

In summary, there are 10 microRNA down-regulated, and three microRNA up-regulated. The main mechanisms of them involve the regulation of proliferation, migration, apoptosis, angiogenesis, inflammation and extracellular matrix, thus affecting the development of alveoli and blood vessels.

\section{LncRNA}

Long non-coding RNA (LncRNA) is a class of RNA molecules with a length of more than $200 \mathrm{nt}$ (32). Instead of encoding proteins, it regulates the expression level of gene in RNA level, like epigenetic regulation, transcriptional regulation, post transcriptional regulation, etc. A Recent study (78) have shown that LncRNA is involved in many important regulatory processes, such as chromosome silencing, genomic imprinting, chromatin modification, transcriptional activation, transcriptional interference, and intranuclear transport. These regulatory roles of LncRNA have also attracted extensive attention. Latest studies have shown that LncRNA has been involved the incidence and development of BPD, and the summary is as follows.

Metastasis associated lung adenocarcinoma transcript 1 (MALAT1) was found in metastasis tissues of patients with non-small cell lung cancer and were overexpressed. MALAT1 was closely related to pulmonary diseases (79). It has been reported that the expression of MALAT1 in lung tissue in WT mice is significantly lower than that in BPD mice. Meanwhile, the expression of MALAT1 in blood samples from preterm infants with BPD was significantly increased compared to normal infants. Knockdown of MALAT1 induced apoptosis in WI38 cells, and the expression of CDC6 was down-regulated (80). A study by Yangi et al., (81), indicates that MALAT1 decreases the expression of miR-129-5p, promoting cell growth and inhibiting the development of bronchopulmonary dysplasia. Besides, MALAT1 increased the expression of high-mobility group protein 1 (HMGB1), which promote inflammation as the disease progressed. Moreover, lncRNA AK033210 is downregulated in $\mathrm{BPD}$, which is associated with Tnc (82).

LncRNA H19 has been found to promote pulmonary fibrosis by regulating the miR-196a/ Collagen I alpha 1 (COL1A1) Axis (83). The researchers (84) find that lncRNA H19 expression is significantly increased in lung tissues of neonatal mice with 
TABLE 1 | List of non-coding RNA currently implicated in bronchopulmonary dysplasia.

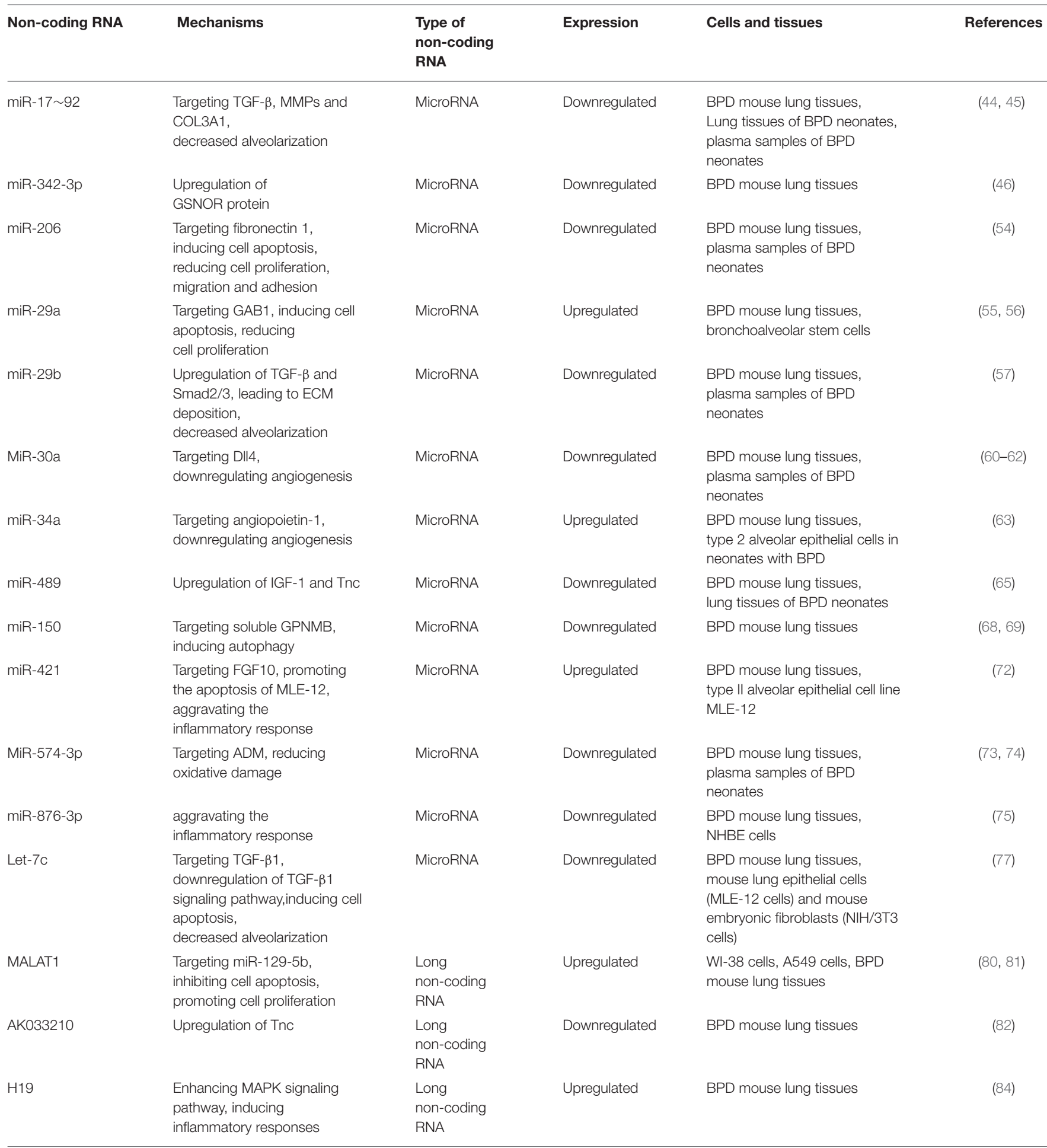

hyperoxia-induced BPD. With the in-depth study, lncRNA H19 was knocked down and overexpressed in A549 cells, and MAPK signaling response and inflammatory factors were detected. In conclusion, lncRNA H19 has also been confirmed to regulate inflammatory responses via MAPK signaling pathway.
Non-coding RNAs currently implicated in bronchopulmonary dysplasia are summarized in the Table 1. The pathogenesis of BPD regulated by these non-coding RNAs is elaborated in the Figure 1. 


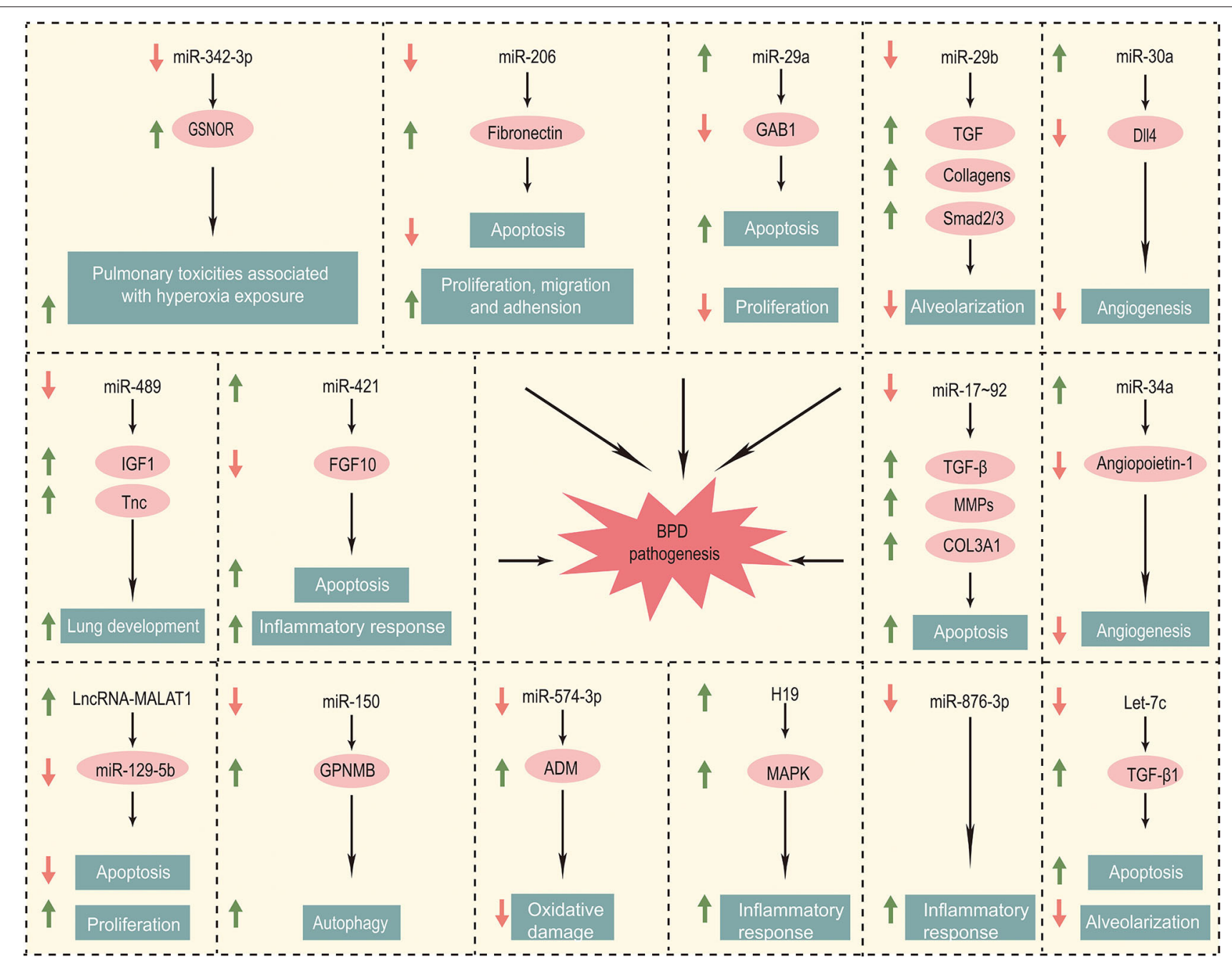

FIGURE 1 | Non-coding RNA involved in the pathogenesis of BPD.

\section{CONCLUSIONS}

$\mathrm{BPD}$ is one of the most serious lung diseases in preterm infants. So far, the pathogenesis of BPD is not yet clear, and there is no effective treatment. In this review, we summarize the non-coding RNA, including 13 microRNA and 3 lncRNA, associated with BPD. As for microRNA associated with BPD, the expression of miR-29a, miR-30a, miR-34a, miR-421 increased and the rest of microRNA decreased. LncRNA MALAT1 and H19 upregulated in BPD, while AK033210 downregulated in BPD. All the changes in microRNA and lncRNA related to BPD can be verified in mice lung tissues. MiR-17 92, miR-206, miR-29b, miR-30a, miR-489, and miR-547-3p can be validated in plasma samples or lung tissues of BPD neonates. As for mechanisms, miR-489 and AK033210 are associated with Tnc. MiR-206, miR-29a, and miR-421 promoted cell apoptosis, while miR-17 92, Let-7c, MALAT1 inhibited cell apoptosis. MiR-30a and miR-34a are associated with angiogenesis, while miR-29b, miR-421, miR-876-3p, and lncRNA H19 regulate inflammatory response. MiR-17 92, miR-29b, and Let-7c are associated with extracellular matrix formation and alveolarization. In summary, non-coding RNA is involved in the incidence and development of BPD by regulating the expression of genes related to proliferation, migration, apoptosis, angiogenesis, inflammation and extracellular matrix in alveolar epithelial cells and vascular endothelial cells.

At present, the clinical diagnosis and treatment of BPD is still lack of high sensitivity and specificity of detection indicators. More and more research results confirm that non-coding RNA plays an important role in the growth and development of lung tissue, so non-coding RNA can be used as a predictor or prognostic indicator of $\mathrm{BPD}$, and also provide a new target for the treatment of BPD. Expression of specific non-coding RNAs are altered in BPD and their levels in the circulation often reflect the changes in expression of their lung-specific counterparts, exploiting these biomolecules as diagnostic tools seems an obvious goal. Some drugs, such as small interfering RNAs (siRNAs) or microRNA mimics, can be designed for 
regulating expression of microRNA, then promote angiogenesis and alveolar development, so as to achieve the purpose of treating $\mathrm{BPD}$. We therefore believe that non-coding RNA is of great significance for the diagnosis and treatment of BPD.

\section{REFERENCES}

1. Jobe AH, Bancalari E. Bronchopulmonary dysplasia. Am J Respir Crit Care Med. (2001) 163:1723-9. doi: 10.1164/ajrccm.163.7.2011060

2. Ehrenkranz RA, Walsh MC, Vohr BR, Jobe AH, Wright LL, Fanaroff $\mathrm{AA}$, et al. Validation of the national institutes of health consensus definition of bronchopulmonary dysplasia. Pediatrics. (2005) 116:135360. doi: 10.1542/peds.2005-0249

3. Higgins RD, Jobe AH, Koso-Thomas M, Bancalari E, Viscardi RM, Hartert TV, et al. Bronchopulmonary dysplasia: executive summary of a workshop. $J$ Pediatr. (2018) 197:300-8. doi: 10.1016/j.jpeds.2018.01.043

4. Jensen EA, Dysart K, Gantz MG, McDonald S, Bamat NA, Keszler M, et al. The diagnosis of bronchopulmonary dysplasia in very preterm infants an evidence-based approach. Am J Respir Crit Care Med. (2019) 200:7519. doi: 10.1164/rccm.201812-2348OC

5. Northway WH Jr, Rosan RC, Porter DY. Pulmonary disease following respirator therapy of hyaline-membrane disease. Bronchopulmonary dysplasia. N Engl J Med. (1967) 276:35768. doi: 10.1056/NEJM196702162760701

6. Baraldi E, Filippone M. Chronic lung disease after premature birth. $N$ Engl J Med. (2007) 357:1946-55. doi: 10.1056/NEJMra067279

7. Mourani PM, Abman SH. Pulmonary vascular disease in bronchopulmonary dysplasia: pulmonary hypertension and beyond. Curr Opin Pediatr. (2013) 25:329-37. doi: 10.1097/MOP.0b013e328360a3f6

8. Voynow JA. New bronchopulmonary dysplasia and chronic lung disease. Paediatr Respir Rev. (2017) 24:17-8. doi: 10.1016/j.prrv.2017.06.006

9. Walsh MC, Szefler S, Davis J, Allen M, van Marter L, Abman S, et al. Summary proceedings from the bronchopulmonary dysplasia group. Pediatrics. (2006) 117:S52-6. doi: 10.1542/peds.2005-0620I

10. Islam JY, Keller RL, Aschner JL, Hartert TV, Moore PE. Understanding the short- and long-term respiratory outcomes of prematurity and bronchopulmonary dysplasia. Am J Respir Crit Care Med. (2015) 192:13456. doi: 10.1164/rccm.201412-2142PP

11. Doyle LW, Cheong JL, Ehrenkranz RA, Halliday HL. Late (> 7 days) systemic postnatal corticosteroids for prevention of bronchopulmonary dysplasia in preterm infants. Cochrane Database Syst Rev. (2017) 10:CD001145. doi: 10.1002/14651858.CD001145.pub4

12. Dargaville PA, Ali SKM, Jackson HD, Williams C, Paoli AGDe. Impact of minimally invasive surfactant therapy in preterm infants at 2932 weeks gestation. Neonatology. (2018) 113:7-14. doi: 10.1159/0004 80066

13. Klingenberg C, Wheeler KI, McCallion N, Morley CJ, Davis PG. Volumetargeted versus pressure-limited ventilation in neonates. Cochrane Database Syst Rev. (2017) 10:CD003666. doi: 10.1002/14651858.CD003666.pub4

14. Stoll BJ, Hansen NI, Bell EF, Shankaran S, Laptook AR, Walsh MC, et al. Neonatal outcomes of extremely preterm infants from the NICHD neonatal research network. Pediatrics. (2010) 126:443-56. doi: 10.1542/peds.2009-2959

15. Stoll BJ, Hansen NI, Bell EF, Walsh MC, Carlo WA, Shankaran $\mathrm{S}$, et al. Trends in care practices, morbidity, and mortality of extremely preterm neonates, 1993-2012. JAMA. (2015) 314:103951. doi: 10.1097/01.aoa.0000482610.95044.1b

16. Eriksson L, Haglund B, Odlind V, Altman M, Ewald U, Kieler H. Perinatal conditions related to growth restriction and inflammation are associated with an increased risk of bronchopulmonary dysplasia. Acta Paediatr. (2015) 104:259-63. doi: 10.1111/apa.12888

17. Laughon MM, Langer JC, Bose CL, Smith PB, Ambalavanan N, Kennedy KA, et al. Prediction of bronchopulmonary dysplasia by postnatal age in extremely premature infants. Am J Respir Crit Care Med. (2011) 183:171522. doi: 10.1164/rccm.201101-0055OC

\section{AUTHOR CONTRIBUTIONS}

YX: conception and design. YW: administrative support. Both authors: final approval of manuscript and manuscript writing.

18. Alvira CM, Morty RE. Can we understand the pathobiology of bronchopulmonary dysplasia? J Pediatr. (2017) 190:2737. doi: 10.1016/j.jpeds.2017.08.041

19. Viscardi RM, Hasday JD. Role of ureaplasma species in neonatal chronic lung disease: epidemiologic and experimental evidence. Pediatr Res. (2009) 65:84-90R. doi: 10.1203/PDR.0b013e31819dc2f9

20. Wright CJ, Kirpalani H. Targeting inflammation to prevent bronchopulmonary dysplasia: can new insights be translated into therapies? Pediatrics. (2011) 128:111-26. doi: 10.1542/peds.2010-3875

21. Jensen EA, Dysart KC, Gantz MG, Carper B, Higgins RD, Keszler M, et al. Association between use of prophylactic indomethacin and the risk for bronchopulmonary dysplasia in extremely preterm infants. J Pediatr. (2017) 186:34-40.e2. doi: 10.1016/j.jpeds.2017.02.003

22. Parad RB, Winston AB, Kalish LA, Gupta M, Thompson I, Sheldon Y, et al. Role of genetic susceptibility in the development of bronchopulmonary dysplasia. J Pediatr. (2018) 203:234-241.e2. doi: 10.1016/j.jpeds.2018.07.099

23. Principi N, di Pietro GM, Esposito S. Bronchopulmonary dysplasia: clinical aspects and preventive and therapeutic strategies. J Transl Med. (2018) 16:36. doi: 10.1186/s12967-018-1417-7

24. Mattick JS, Makunin IV. Non-coding RNA. Hum Mol Genet. (2006) 15(Spec No 1):R17-29. doi: 10.1093/hmg/ddl046

25. Sloan KE, Warda AS, Sharma S, Entian KD, Lafontaine DLJ, Bohnsack MT. Tuning the ribosome: the influence of rRNA modification on eukaryotic ribosome biogenesis and function. RNA Biol. (2017) 14:113852. doi: 10.1080/15476286.2016.1259781

26. Ramos J, Fu D. The emerging impact of tRNA modifications in the brain and nervous system. Biochim Biophys Acta Gene Regul Mech. (2019) 1862:41228. doi: 10.1016/j.bbagrm.2018.11.007

27. Bohnsack MT, Sloan KE. Modifications in small nuclear RNAs and their roles in spliceosome assembly and function. Biol Chem. (2018) 399:126576. doi: 10.1515/hsz-2018-0205

28. Kufel J, Grzechnik P. Small nucleolar RNAs tell a different tale. Trends Genet. (2019) 35:104-17. doi: 10.1016/j.tig.2018.11.005

29. Ruigrok MJR, Frijlink HW, Hinrichs WLJ. Pulmonary administration of small interfering RNA: the route to go? J Control Release. (2016) 235:1423. doi: 10.1016/j.jconrel.2016.05.054

30. Salzman J. Circular RNA expression: its potential regulation and function. Trends Genet. (2016) 32:309-16. doi: 10.1016/j.tig.2016.03.002

31. Iqbal MA, Arora S, Prakasam G, Calin GA, Syed MA. MicroRNA in lung cancer: role, mechanisms, pathways and therapeutic relevance. Mol Aspects Med. (2019) 70:3-20. doi: 10.1016/j.mam.2018.07.003

32. Quinn JJ, Chang HY. Unique features of long non-coding RNA biogenesis and function. Nat Rev Genet. (2016) 17:47-62. doi: 10.1038/nrg.2015.10

33. Vencken SF, Greene CM, McKiernan PJ. Non-coding RNA as lung disease biomarkers. Thorax. (2015) 70:501-3. doi: 10.1136/thoraxjnl-2014-206193

34. Lu W, Zhang H, Niu Y, Wu Y, Sun W, Li H, et al. Long non-coding RNA linc00673 regulated non-small cell lung cancer proliferation, migration, invasion and epithelial mesenchymal transition by sponging miR-150-5p. Mol Cancer. (2017) 16:118. doi: 10.1186/s12943-017-0685-9

35. Musri MM, Coll-Bonfill N, Maron BA, Peinado VI, Wang RS, Altirriba J, et al. MicroRNA dysregulation in pulmonary arteries from chronic obstructive pulmonary disease relationships with vascular remodeling. Am J Respir Cell Mol Biol. (2018) 59:490-9. doi: 10.1165/rcmb.2017-0040OC

36. Chen Y, Mao ZD, Shi YJ, Qian Y, Liu ZG, Yin XW, et al. Comprehensive analysis of miRNA-mRNA-lncRNA networks in severe asthma. Epigenomics. (2019) 11:115-31. doi: 10.2217/epi-2018-0132

37. Liu Q, Du J, Yu X, Xu J, Huang F, Li X, et al. miRNA-200c-3p is crucial in acute respiratory distress syndrome. Cell Discov. (2017) 3:17021. doi: $10.1038 /$ celldisc. 2017.21 
38. Matsui M, Corey DR. Non-coding RNAs as drug targets. Nat Rev Drug Discov. (2017) 16:167-79. doi: 10.1038/nrd.2016.117

39. Lu TX, Rothenberg ME. MicroRNA. J Allergy Clin Immunol. (2018) 141:12027. doi: 10.1016/j.jaci.2017.08.034

40. Beermann J, Piccoli MT, Viereck J, Thum T. Non-coding RNAs in development and disease: background, mechanisms, and therapeutic approaches. Physiol Rev. (2016) 96:1297325. doi: 10.1152/physrev.00041.2015

41. Sayed D, Abdellatif M. MicroRNAs in development and disease. Physiol Rev. (2011) 91:827-87. doi: 10.1152/physrev.00006.2010

42. Bonauer A, Dimmeler S. The microRNA-17-92 cluster: still a miRacle? Cell Cycle. (2009) 8:3866-73. doi: 10.4161/cc.8.23.9994

43. Lu Y, Okubo T, Rawlins E, Hogan BL. Epithelial progenitor cells of the embryonic lung and the role of microRNAs in their proliferation. Proc Am Thorac Soc. (2008) 5:300-4. doi: 10.1513/pats.200710-162DR

44. Robbins ME, Dakhlallah D, Marsh CB, Rogers LK, Tipple TE. Of mice and men: correlations between microRNA-17 92 cluster expression and promoter methylation in severe bronchopulmonary dysplasia. Am J Physiol Lung Cell Mol Physiol. (2016) 311:L981-1984. doi: 10.1152/ajplung.00390.2016

45. Rogers LK, Robbins M, Dakhlallah D, Yang Z, Lee LJ, Mikhail M, et al. Attenuation of miR-17 92 cluster in bronchopulmonary dysplasia. Ann Am Thorac Soc. (2015) 12:1506-13. doi: 10.1513/AnnalsATS.201501-058OC

46. Raffay TM, Dylag AM, di Fiore JM, Smith LA, Einisman HJ, Li $\mathrm{Y}$, et al. S-nitrosoglutathione attenuates airway hyperresponsiveness in murine bronchopulmonary dysplasia Mol Pharmacol. (2016) 90:41826. doi: 10.1124/mol.116.104125

47. Zhang X, Wang H, Shi Y, Peng W, Zhang S, Zhang W, et al. Role of bone marrow-derived mesenchymal stem cells in the prevention of hyperoxia-induced lung injury in newborn mice. Cell Biol Int. (2012) 36:58994. doi: 10.1042/CBI20110447

48. Soikkeli J, Podlasz P, Yin M, Nummela P, Jahkola T, Virolainen S, et al. Metastatic outgrowth encompasses COL-I, FN1, and POSTN up-regulation and assembly to fibrillar networks regulating cell adhesion, migration, and growth. Am J Pathol. (2010) 177:387-403. doi: 10.2353/ajpath.2010.090748

49. Wijelath ES, Rahman S, Murray J, Patel Y, Savidge G, Sobel M. Fibronectin promotes VEGF-induced CD34 cell differentiation into endothelial cells. $J$ Vasc Surg. (2004) 39:655-60. doi: 10.1016/j.jvs.2003.10.042

50. Fujiu K, Manabe I, Nagai R. Renal collecting duct epithelial cells regulate inflammation in tubulointerstitial damage in mice. J Clin Invest. (2011) 121:3425-41. doi: 10.1172/JCI57582

51. Lumeng CN, Deyoung SM, Bodzin JL, Saltiel AR. Increased inflammatory properties of adipose tissue macrophages recruited during diet-induced obesity. Diabetes. (2007) 56:16-23. doi: 10.2337/db06-1076

52. Kallapur SG, Jobe AH. Contribution of inflammation to lung injury and development. Arch Dis Child Fetal Neonatal Ed. (2006) 91:F1325. doi: 10.1136/adc.2004.068544

53. McAdams RM, Vanderhoeven J, Beyer RP, Bammler TK, Farin FM, Liggitt HD, et al. Choriodecidual infection downregulates angiogenesis and morphogenesis pathways in fetal lungs from Macaca nemestrina. PLoS ONE. (2012) 7:e46863. doi: 10.1371/journal.pone.0046863

54. Zhang X, Xu J, Wang J, Gortner L, Zhang S, Wei X, et al. Reduction of microRNA-206 contributes to the development of bronchopulmonary dysplasia through up-regulation of fibronectin 1. PLoS ONE. (2013) 8:e74750. doi: 10.1371/journal.pone.0074750

55. Dong J, Carey WA, Abel S, Collura C, Jiang G, Tomaszek S, et al. MicroRNA-mRNA interactions in a murine model of hyperoxiainduced bronchopulmonary dysplasia. BMC Genomics. (2012) 13:204. doi: 10.1186/1471-2164-13-204

56. Hu Y, Xie L, Yu J, Fu H, Zhou D, Liu H. Inhibition of microRNA-29a alleviates hyperoxia-induced bronchopulmonary dysplasia in neonatal mice via upregulation of GAB1. Mol Med. (2019) 26:3. doi: 10.1186/s10020-019-0127-9

57. Durrani-Kolarik S, Pool CA, Gray A, Heyob KM, Cismowski MJ, Pryhuber G, et al. miR-29b supplementation decreases expression of matrix proteins and improves alveolarization in mice exposed to maternal inflammation and neonatal hyperoxia. Am J Physiol Lung Cell Mol Physiol. (2017) 313:L3391349. doi: 10.1152/ajplung.00273.2016

58. Bridge G, Monteiro R, Henderson S, Emuss V, Lagos D, Georgopoulou $\mathrm{D}$, et al. The microRNA-30 family targets DLL4 to modulate endothelial cell behavior during angiogenesis. Blood.

(2012) 120:5063-72. doi: 10.1182/blood-2012-04-423004

59. Jiang Q, Lagos-Quintana M, Liu D, Shi Y, Helker C, Herzog $\mathrm{W}$, et al. miR-30a regulates endothelial tip cell formation and arteriolar branching. Hypertension. (2013) 62:5928. doi: 10.1161/HYPERTENSIONAHA.113.01767

60. Wu YT, Chen WJ, Hsieh WS, Tsao PN, Yu SL, Lai CY, et al. MicroRNA expression aberration associated with bronchopulmonary dysplasia in preterm infants: a preliminary study. Respir Care. (2013) 58:152735. doi: $10.4187 /$ respcare. 02166

61. Zhang Y, Coarfa C, Dong X, Jiang W, Hayward-Piatkovskyi B, Gleghorn JP et al. MicroRNA-30a as a candidate underlying sex-specific differences in neonatal hyperoxic lung injury: implications for BPD. Am J Physiol Lung Cell Mol Physiol. (2019) 316:L144-1156. doi: 10.1152/ajplung.00372.2018

62. Zhang Y, Dong X, Lingappan K. Role of HIF-1 $\alpha$-miR30a-snail axis in neonatal hyperoxic lung injury. Oxid Med Cell Longev. (2019) 2019:8327486. doi: 10.1155/2019/8327486

63. Syed M, Das P, Pawar A, Aghai ZH, Kaskinen A, Zhuang ZW, et al. Hyperoxia causes miR-34a-mediated injury via angiopoietin-1 in neonatal lungs. Nat Commun. (2017) 8:1173. doi: 10.1038/s41467-017-01349-y

64. Ruiz-Camp J, Quantius J, Lignelli E, Arndt PF, Palumbo F, Nardiello C, et al. Targeting miR-34a/Pdgfra interactions partially corrects alveologenesis in experimental bronchopulmonary dysplasia. EMBO Mol Med. (2019) 11:e9448. doi: 10.15252/emmm.201809448

65. Olave N, Lal CV, Halloran B, Pandit K, Cuna AC, Faye-Petersen OM, et al. Regulation of alveolar septation by microRNA-489. Am J Physiol Lung Cell Mol Physiol. (2016) 310:L476-87. doi: 10.1152/ajplung.00145.2015

66. Rose AA, Annis MG, Dong Z, Pepin F, Hallett M, Park M, et al ADAM10 releases a soluble form of the GPNMB/Osteoactivin extracellular domain with angiogenic properties. PLOS ONE. (2010) 5:e12093. doi: 10.1371/journal.pone.0012093

67. Li B, Castano AP, Hudson TE, Nowlin BT, Lin SL, Bonventre JV, et al. The melanoma-associated transmembrane glycoprotein Gpnmb controls trafficking of cellular debris for degradation and is essential for tissue repair. FASEB J. (2010) 24:4767-81. doi: 10.1096/fj.10.154757

68. Bhaskaran M, Xi D, Wang Y, Huang C, Narasaraju T, Shu W, et al. Identification of microRNAs changed in the neonatal lungs in response to hyperoxia exposure. Physiol Genomics. (2012) 44:970-80. doi: 10.1152/physiolgenomics.00145.2011

69. Narasaraju T, Shukla D, More S, Huang C, Zhang L, Xiao X, et al. Role of microRNA-150 and glycoprotein nonmetastatic melanoma protein B in angiogenesis during hyperoxia-induced neonatal lung injury. Am J Respir Cell Mol Biol. (2015) 52:253-61. doi: 10.1165/rcmb.2013-0021OC

70. El Agha E, Al Alam D, Carraro G, MacKenzie B, Goth K, De Langhe SP, et al. Characterization of a novel fibroblast growth factor 10 (Fgf10) knock-in mouse line to target mesenchymal progenitors during embryonic development. PLoS ONE. (2012) 7:e38452. doi: 10.1371/journal.pone.0038452

71. Mohamed WA, Aseeri MA. Cord blood fibroblast growth factor-10 as a possible predictor of bronchopulmonary dysplasia in preterm infants. $J$ Neonatal Perinatal Med. (2014) 7:101-5. doi: 10.3233/NPM-1476613

72. Yuan HS, Xiong DQ, Huang F, Cui J, Luo H. MicroRNA-421 inhibition alleviates bronchopulmonary dysplasia in a mouse model via targeting Fgf10. J Cell Biochem. (2019) 120:16876-87. doi: 10.1002/jcb.28945

73. Vadivel A, Abozaid S, van Haaften T, Sawicka M, Eaton F, Chen $\mathrm{M}$, et al. Adrenomedullin promotes lung angiogenesis, alveolar development, and repair. Am J Respir Cell Mol Biol. (2010) 43:152-60. doi: 10.1165/rcmb.2009-0004OC

74. Gong X, Qiu J, Qiu G, Cai C. Adrenomedullin regulated by miRNA-5743 p protects premature infants with bronchopulmonary dysplasia. Biosci Rep. (2020) 40:BSR20191879. doi: 10.1042/BSR20191879

75. Lal CV, Olave N, Travers C, Rezonzew G, Dolma K, Simpson A, et al. Exosomal microRNA predicts and protects against severe bronchopulmonary dysplasia in extremely premature infants. JCI Insight. (2018) 3:e93994. doi: 10.1172/jci.insight.93994

76. Zhao B, Han H, Chen J, Zhang Z, Li S, Fang F, et al. MicroRNA let-7c inhibits migration and invasion of human non-small cell lung cancer by targeting ITGB3 and MAP4K3. Cancer Lett. (2014) 342:4351. doi: $10.1016 /$ j.canlet.2013.08.030 
77. Chen XQ, Wu SH, Luo YY, Li BJ, Li SJ, Lu HY, et al. Lipoxin $\mathrm{A}(4)$ attenuates bronchopulmonary dysplasia via upregulation of let-7c and downregulation of TGF- $\beta(1)$ signaling pathway. Inflammation. (2017) 40:2094-108. doi: 10.1007/s10753-017-0 649-7

78. Ransohoff JD, Wei Y, Khavari PA. The functions and unique features of long intergenic non-coding RNA. Nat Rev Mol Cell Biol. (2018) 19:14357. doi: $10.1038 / \mathrm{nrm} .2017 .104$

79. Guo F, Li Y, Liu Y, Wang J, Li Y, Li G. Inhibition of metastasisassociated lung adenocarcinoma transcript 1 in CaSki human cervical cancer cells suppresses cell proliferation and invasion. Acta Biochim Biophys Sin. (2010) 42:224-9. doi: 10.1093/abbs/ gmq008

80. Cai C, Qiu J, Qiu G, Chen Y, Song Z, Li J, et al. Long non-coding RNA MALAT1 protects preterm infants with bronchopulmonary dysplasia by inhibiting cell apoptosis. BMC Pulm Med. (2017) 17:199. doi: 10.1186/s12890-017-0524-1

81. Yangi R, Huang H, Zhou Q. Long noncoding RNA MALAT1 sponges miR-129-5p to regulate the development of bronchopulmonary dysplasia by increasing the expression of HMGB1. J Int Med Res. (2020) 48:300060520918476. doi: 10.1177/03000605209 18476

82. Bao TP, Wu R, Cheng HP, Cui XW, Tian ZF. Differential expression of long non-coding RNAs in hyperoxia-induced bronchopulmonary dysplasia. Cell Biochem Funct. (2016) 34:299-309. doi: 10.1002/cbf.3190
83. Lu Q, Guo Z, Xie W, Jin W, Zhu D, Chen S, et al. The lncRNA H19 mediates pulmonary fibrosis by regulating the miR-196a/COL1A1 axis. Inflammation. (2018) 41:896-903. doi: 10.1007/s10753-018-0744-4

84. Mo W, Li Y, Chang W, Luo Y, Mai B, Zhou J. The role of LncRNA $\mathrm{H} 19$ in MAPK signaling pathway implicated in the progression of bronchopulmonary dysplasia. Cell Transplant. (2020) 29:963689720918294. doi: 10.1177/0963689720918294

Conflict of Interest: The authors declare that the research was conducted in the absence of any commercial or financial relationships that could be construed as a potential conflict of interest.

Publisher's Note: All claims expressed in this article are solely those of the authors and do not necessarily represent those of their affiliated organizations, or those of the publisher, the editors and the reviewers. Any product that may be evaluated in this article, or claim that may be made by its manufacturer, is not guaranteed or endorsed by the publisher.

Copyright $\odot 2021 \mathrm{Xi}$ and Wang. This is an open-access article distributed under the terms of the Creative Commons Attribution License (CC BY). The use, distribution or reproduction in other forums is permitted, provided the original author(s) and the copyright owner(s) are credited and that the original publication in this journal is cited, in accordance with accepted academic practice. No use, distribution or reproduction is permitted which does not comply with these terms. 